\title{
A PRÉ-ESCOLA E O DIREITO À EDUCAÇÃO: APORTES PARA UM DEBATE
}

\author{
LUIZ CARLOS GIL ESTEVES
}

\section{RESUMO}

O objetivo deste artigo é refletir, com base em números do Instituto Brasileiro de Geografia e Estatística (IBGE), sobre o processo de oferta da educação pré-escolar no período de 2003 a 2014, tendo em vista o conjunto de leis que determina a sua universalização obrigatória dessa etapa até o fim de 2016. Assim, ainda que o avanço nesse atendimento tenha sido expressivo, constatou-se um déficit de cobertura superior a 600 mil crianças de 4 e 5 anos. Os mais excluídos são os sujeitos provenientes do estrato dos $25 \%$ mais pobres da população, de raçal cor preta e residentes em áreas rurais, sobretudo nas regiões Norte e Centro-Oeste. Não foi percebido maior impacto nem com a adoção de novos parâmetros para o financiamento educacional nem com a promulgação das leis que obrigam tal oferta universal, no sentido de alterar o ritmo progressivo das matrículas verificado, como também não se percebeu relação direta entre maior cobertura e melhores indicadores de qualidade.

PALAVRAS-CHAVE EDUCAÇÃO PRÉ-ESCOLAR - DIREITO À EDUCAÇÃO • LEGISLAÇÃO DA EDUCAÇÃO • INDICADORES EDUCACIONAIS. 


\section{LA PREESCUELA Y EL DERECHO A LA EDUCACIÓN: APORTES PARA UN DEBATE \\ RESUMEN}

El objetivo de este artículo es el de reflexionar, en base a números provenientes del Instituto Brasileiro de Geografia e Estatística (IBGE), sobre el proceso de oferta de la educación preescolar entre 2003 y 2014, teniendo en cuenta el conjunto de leyes que determina su universalización obligatoria hasta fines del 2016. Aunque el avance en dicha atención fue expresivo, se constató un déficit de cobertura superior a 600 mil niños entre 4 y 5 años. Los principales excluidos son los sujetos provenientes del estrato 25\% más pobre de la población, de raza/color negro y residentes en las áreas rurales, sobre todo en las regiones Norte y Centro Oeste. No se detectó un gran impacto tanto con la adopción de nuevos parámetros para la financiación educacional como con la promulgación de las leyes que obligan tal oferta universal, en el sentido de alterar el ritmo progresivo de las matrículas que se verificó durante los años investigados, así como tampoco se percibió una relación directa entre mayor cobertura y mejores indicadores de calidad.

PALABRAS CLAVE EDUCACIÓN PREESCOLAR - DERECHO A LA EDUCACIÓN • LEGISLACIÓN DE LA EDUCACIÓN • INDICADORES EDUCACIONALES.

\section{PRESCHOOL AND THE RIGHT TO EDUCATION: CONTRIBUTIONS TO A DEBATE}

ABSTRACT

This article aims to reflect on the process of offering pre-school education from 2003 to 2014. It is based on figures from the Brazilian Institute of Geography and Statistics (IBGE) and guided by the set of laws that determine the compulsory universalization of pre-school education by the end of 2016. Thus, even if the number of children attending school has been expressive, there is a deficit of more than 600,000 places for 4 and 5 year-old children. Most of the children excluded come from the poorest $25 \%$ stratum of the population, who are black and reside in rural areas, especially in the North and Midwest regions. No impact was detected in the change of the progressive pace of enrollment, neither with the adoption of new parameters for the educational funding nor with the legislation that establishes preschool education as universal and compulsory. Also, no direct relationship between more places and better quality indicators was detected.

KEYWORDS PRE-SCHOOL EDUCATION • RIGHT TO EDUCATION • EDUCATION LEGISLATION • EDUCATIONAL INDICATORS. 
1 Ainda que não seja objeto da análise realizada neste estudo, vale destacar a existência de controvérsias acerca da exclusão das creches da obrigatoriedade preconizada por este aparato legal, conforme argumentam, entre outros, Didonet (2014) e Cavalcanti e Maragon (2011).

2 Isso porque, até aquela data, a obrigatoriedade de oferta educacional pública e gratuita restringia-se à faixa de 6 a 14 anos, idealmente constituída pelo ensino fundamental.

\section{INTRODUÇÃO}

Desde 11 de novembro de 2009, a Emenda Constitucional n. 59 - EC 59/09 - (BRASIL, 2009) determina como obrigatória e gratuita a oferta, pelo Estado brasileiro, de educação básica dos 4 aos 17 anos de idade, ${ }^{1}$ assegurando a sua oferta inclusive para todos os que a ela não tiveram acesso na idade adequada. Ainda que não contemplasse a totalidade das demandas educacionais da sociedade brasileira, traduzidas pelo amplo ingresso, nos termos da lei, a todos os segmentos da chamada educação nacional, tal medida veio coroar a vitória dos movimentos sociais organizados em prol da ampliação do direito à educação. Nesse caso particular, o direito ao acesso àquela etapa que Cury (2000, 2008) considera um dos maiores ganhos presentes na atual Lei de Diretrizes e Bases da Educação Nacional, Lei n. 9.394, de 20/12/96 - LDB - (BRASIL, 1996), qual seja, a educação básica, etapa essa que, ainda segundo Cury, além de constituir um conceito novo, ao mesmo tempo, traduz um direito e também uma forma de organização da educação no país. ${ }^{2}$

Entretanto, somente em 2013, por meio da Lei n. 12.796, de 4 de abril, é que a LDB será finalmente alterada, através 
de uma nova redação de seu Artigo $4^{\circ}$, estabelecendo que o dever do Estado com a educação escolar pública se expressa, entre outras medidas, pela oferta de educação básica obrigatória e gratuita àquela faixa etária (4 a 17 anos), oferta essa que, idealmente, tem seu início na pré-escola, ${ }^{3}$ passa pelo ensino fundamental e desemboca no ensino médio. Para atender a tal obrigatoriedade, e no que pese a matrícula ficar a cargo dos pais e responsáveis, ${ }^{4}$ as redes municipais e estaduais de ensino devem (ou deveriam) se adequar, até o ano de 2016, tanto física quanto pedagogicamente, para acolher condignamente os alunos dessa faixa etária.

Por sua vez, outro dispositivo legal, a Lei n. 13.005, de 25 de junho de 2014 (BRASIL, 2014), que aprova o Plano Nacional de Educação (PNE), determinando as diretrizes, metas e estratégias para a política educacional dos dez anos seguintes (2014-2024), estabelece, já em sua primeira meta, e em total consonância com a LDB/96, a universalização, até o final de 2016, da educação infantil na pré-escola para as crianças de 4 a 5 anos de idade, ampliando ainda a oferta dessa educação em creches, de forma a atender, pelo menos, $50 \%$ das crianças de 0 a 3 anos até o fim da vigência do Plano.

No entanto, apesar das determinações legais evocadas, decorridos mais de três anos desde a alteração da LDB/96 (ou mais de seis anos, se consideramos, a exemplo de outros, a EC 59/09 como marco regulatório dessa obrigatoriedade), um rápido olhar sobre a evolução das taxas de atendimento da educação infantil no país, já neste século XXI, deixa claro que dificilmente os objetivos traçados pelas diferentes - mas convergentes leis serão alcançados. Por esse motivo, voltar os olhos mais detidamente para a análise de tais números, ressignificando-os, através de seu entrecruzamento com outros indicadores e variáveis, é tarefa necessária, no sentido de identificar novos e/ou ratificar antigos obstáculos que se interpõem ao cumprimento dessa norma constitucional, cujo resultado é a negação, a centenas de milhares de crianças brasileiras, das prerrogativas inerentes à oferta pública, gratuita e de qualidade dessa importantíssima etapa da educação básica.

Por essa linha, ainda que concordemos que outro expressivo ganho contido, desde sua promulgação, na atual
3 Uma interessante análise acerca da obrigatoriedade de matrícula em estabelecimentos públicos, preconizada pela Lei n. 12.796, para as crianças de 4 e 5 anos constituir ampliação ou recuo do direito na esfera da educação infantil pode ser encontrada em Campos e Barbosa (2016).

4 Para um maior aprofundamento crítico dessa responsabilização parental acerca da matrícula na pré-escola, que acaba por culpabilizar os pais e responsáveis pela não frequência escolar, eximindo o Estado de aprimorar a baixa qualidade que caracteriza a sua própria oferta educacional, sobretudo aos setores populares, vale a pena conhecer os argumentos de Didonet (2014) Cavalcanti e Maragon (2011) e Cury e Ferreira (2010) 
5 De acordo com o site, "o Observatório do PNE é uma plataforma online que tem como objetivo monitorar os indicadores referentes a cada uma das respectivas estratégias [...]. A ideia é que a ferramenta possa apoiar gestores públicos, educadores pesquisadores
LDB, tenha sido a inclusão das creches como primeira etapa da educação infantil - e, por conseguinte, de toda a educação básica -, neste artigo, vamos nos deter exclusivamente na abordagem de números relativos ao seu segundo segmento, a educação pré-escolar, procedimento esse que caracteriza o processo de pesquisa aqui empreendido como estritamente documental. Tal recorte se dá, basicamente, por duas razões: a primeira por estarmos às vésperas de expirar o prazo estabelecido pela LDB para a universalização da pré-escola, qual seja, o ano de 2016, situação essa que, na época de elaboração deste artigo, impunha às redes municipais de ensino, principais responsáveis no âmbito legal pela oferta dessa etapa escolar, exíguos seis meses para o cumprimento dessa determinação legal; e a segunda decorrente da grande profusão de dados acerca do atendimento à educação infantil como um todo, o que certamente extrapolaria os limites textuais aqui impostos.

Outras escolhas a serem explicitadas dizem respeito ao marco temporal e ao banco de dados de que lançamos mão. Quanto ao primeiro, o período visitado vai de 2003 até 2014, série de 12 anos que abrange, não coincidentemente, o início do primeiro mandato de governo do então presidente Luiz Inácio Lula da Silva, e termina no último ano do primeiro mandato da presidenta Dilma Rousseff; a demarcação inicial (2003) deu-se por conta de tal período ser reconhecido, até mesmo por opositores dos governos desde então instituídos, como uma era de "aumentos significativos das matrículas [...] na pré-escola e no ensino superior” (DURHAM, 2010, p. 154), sintomas, portanto, de ampliação da conquista de direitos sociais por sujeitos até então excluídos de seu usufruto (TELLES, 1999); a demarcação final se deu pelo fato de ser o ano de 2014 o último de divulgação dos dados provenientes da Pesquisa Nacional por Amostra de Domicílios (Pnad), do Instituto Brasileiro de Geografia e Estatística (IBGE).

No que diz respeito à coleta dos dados estatísticos, estes foram, salvo raras exceções, baixados, via internet e quase que exclusivamente, do site Observatório do PNE (http://www. observatoriodopne.org.br/), ${ }^{5}$ cuja profusão e confiabilidade das informações atualmente ofertadas vêm-no configurando 
como importante ferramenta de acompanhamento, controle e avaliação na área educacional. Tais dados pré-existentes, originários da Pnad/IBGE, foram retrabalhados de acordo com os objetivos estabelecidos para esta investigação, inscrevendo-a no campo da pesquisa documental. Silva et al. $(2009$, p. 2) destacam que tal método se caracteriza, no âmbito da abordagem qualitativa, por tentar apreender a realidade social "de forma indireta por meio da análise dos inúmeros tipos de documentos produzidos pelo homem". Assim, a escolha metodológica aqui efetivada relaciona-se diretamente

[...] à natureza e aos objetivos da pesquisa, assim como também às condições estruturais que dispõe o pesquisador para responder às suas questões de investigação e apreender o seu objeto de estudo. (SILVA et al., 2009, p. 2)

Nesse sentido, considerando que todo percurso investigativo é marcado pela concepção epistemológica à qual se filia o investigador (descartando-se, portanto, qualquer suposta tentativa de neutralidade), cabe ressaltar que esta análise tem uma abordagem de caráter compreensivo, com enfoque mais crítico, definida por Alvarado e García (2008) como constitutiva do paradigma sociocrítico. Tal paradigma, fundamentado na crítica social, tem como principal objetivo promover transformações na sociedade, assumindo como norte, entre outros aspectos, a construção do conhecimento sempre a partir dos interesses provenientes dos grupos historicamente à margem dos processos econômicos que se efetivam em sociedades marcadas por processos de exclusão (ALVARADO; GARCÍA, 2008).

Vale sublinhar que este estudo não tem a pretensão de constituir um "ponto de chegada" - no senso estrito que a expressão comporta - no campo da educação infantil, especialmente no que diz respeito à educação pré-escolar. Isso porque, dentre uma série de outros limites, não conta com dados referentes aos anos de 2015 e 2016 da mesma natureza dos aqui utilizados, os quais seriam imprescindíveis para uma análise comparativa capaz de "fechar o ciclo" temporal da oferta obrigatória, imposta pelo aparato legal, a todas as crianças de 4 e 5 anos do país.

Também não se pretende fazer uma discussão mais aprofundada acerca da pluralidade de aspectos que medeiam 
6 Para tanto entre uma série de importantes estudos, vale conhecer o trabalho seminal de Fúlvia Rosemberg (1999), em que a autora analisa prioritariamente, mas não apenas, - processo de exclusão de crianças negras e pobres, decorrente do tipo de expansão dessa oferta educacional desde os anos 1970. Outro marco de destaque é o estudo de Kappel, Carvalho e Kramer (2001), em que as autoras revisam alguns conceitos na área da educação infantil e analisam, à luz dessa revisão, dados relativos às crianças de $\mathrm{O}$ a 6 anos, provenientes da Pesquisa sobre Padrões de Vida, feita pelo IBGE em 1996 e 1997.

7 Em outro artigo, no qual analisam dados provenientes de estudos empíricos, divulgados entre 1996 e 2003, acerca da qualidade da educação nas instituições de educação infantil no país, Campos, Füllgraf e Wigger (2006, p. 120), ao listarem alguns dos obstáculos detectados nessas pesquisas. fornecem indícios sobre quais seriam alguns dos requisitos mínimos no sentido de responder a tal padrão de qualidade: "as políticas desenvolvidas pelas diferentes instâncias governamentais nem sempre respeitam as diretrizes legais ou são coerentes com elas. [...] Além disso, em muitos estados e municípios persiste a mentalidade de que creches e pré-escolas não necessitam de profissionais qualificados e bem remunerados, de serviços eficientes de supervisão, não requerem prédios e equipamentos adaptados às necessidades infantis, não precisam de livros nem de brinquedos, e assim por diante" a oferta (ou não) da educação pré-escolar no país ao longo dos anos. ${ }^{6}$ Nosso objetivo restringe-se ao esforço de sistematizar analiticamente dados relativos à frequência pré-escolar no Brasil, tendo em vista, até onde foi possível perceber, o pouco material disponível sobre o assunto nos anos aqui enunciados. Diante disso, nossa abordagem se voltará prioritariamente para o desvelamento de tais números, bem como seu entrecruzamento com outras informações capazes de aprofundar os seus sentidos.

Ainda sobre as limitações deste trabalho, convém explicitar que, em nosso entender, estar na escola não é sinônimo de ser atendido com qualidade, debate esse que, embora de muita importância, não nos propomos aqui a realizar. No entanto, ressaltamos nossa concordância com algumas premissas básicas desse campo de análise, que podem ser resumidas nas palavras de Maria Malta Campos (2013), quando a autora, avaliando os embates acerca do conceito de qualidade da educação na América Latina, sobretudo aquela afeta aos pequenos, oferece pistas capazes de nos guiar através da complexidade que permeia tal discussão:

[...] refletir sobre a qualidade da educação, nessa parte
do mundo, implica refletir sobre a desigualdade de opor-
tunidades educacionais, os processos de exclusão social
vividos dentro e fora da escola e as contradições entre
os objetivos econômicos e as metas das políticas educa-
cionais. Implica situar os diversos discursos sobre a qua-
lidade, identificando quem fala e de onde fala. Implica
reconhecer que existem conflitos e disputas na definição
do que seja qualidade da educação. (CAMPos, 2013, p. 5)7

Entretanto, para além de interpretações reducionistas, se concordamos com Oliveira (2007) que a ampliação do acesso à escola ocorrido nas últimas décadas já é, por si mesmo, um indicador de que a qualidade da educação está melhorando, uma vez que beneficia estratos da população historicamente excluídos, não se pode negar que essa maior presença da sociedade como um todo dentro dos muros escolares, conforme também atestam os dados aqui visitados, enseja a produção e o fortalecimento de uma nova cultura 
escolar. Cultura essa cujos desdobramentos, embora não possam ser detectados em curto prazo - já que demandam um tempo de maturação e, sobretudo, apropriação, de fato, de um relativamente novo modus vivendi por parte das classes populares -, com certeza se farão sentir, na forma de novas reivindicações (aqui certamente incluídas aquelas por melhor qualidade) em um breve futuro.

Por último, é oportuno destacar que nossa opção de trabalhar preponderantemente com dados estatísticos encontra-se respaldada no compromisso de tratá-los de forma leve e acessível, na tentativa de romper com alguns limites ainda hoje observados na esfera da pesquisa em educação, em especial, sua resistência de estabelecer um diálogo profícuo com tais ferramentas "quantitativas". Desse modo, tais dados são aqui concebidos como elementos fundamentais para uma primeira, mas consistente, aproximação com o universo investigado, capazes, portanto, de oferecer pistas importantes ou, no sentido figurado, chaves-mestras para uma entrada mais segura em alguns campos de visita indispensável, com vistas ao seu melhor desvelamento. Sendo assim, essa contribuição é mais bem entendida se interpretada, dentro de suas limitações, como elemento capaz de mapear territórios, levantar discussões e, quem sabe, suscitar outras pesquisas acerca das fragilidades e avanços observados, no sentido do aprimoramento da oferta obrigatória dessa etapa educacional por parte do poder público à sociedade brasileira, uma vez que este é, em última instância, o responsável direto por ela.

Visando à organização de seu conteúdo, este artigo se encontra, basicamente, dividido em quatro itens. O primeiro, representado por esse marco de discussão introdutório. O segundo, em que são apresentados, na forma de gráficos e tabelas, os dados que servem de base para nossas reflexões; por sua vez, tais dados encontram-se agrupados em dois subitens: um contemplando os números gerais do país, em diálogo com dados regionais, por localidade, raça/cor e renda familiar per capita; e outro abordando números regionais, agregados com dados de suas respectivas unidades federativas, localidade, raça/cor e renda familiar per capita. O terceiro, 
em que são feitas as considerações finais acerca de nosso objeto de estudo em consonância com o atual momento político por que passa a sociedade brasileira. E o quarto e último, com as obras bibliográficas citadas.

\section{EDUCAÇÃO PRÉ-ESCOLAR: O QUE DIZEM OS NÚMEROS?} DADOS GERAIS

Conforme bem expressa o Gráfico 1, muito se avançou no atendimento à educação pré-escolar no Brasil. Se tal cobertura estava, em 2003, no patamar de 70\%, em 12 anos, sobe quase 20 pontos percentuais, chegando a $89,1 \%$. Entretanto, se tomamos como referência a exigência de oferta obrigatória e gratuita por parte do Estado a esse segmento, conforme preconiza a legislação educacional em vigência, constatamos que muito ainda teria de ser feito para alcançar a universalização dessa etapa até o fim de 2016. Isso porque - e no que pesem estudos tais como os de Campos, Esposito e Gimenes (2014), atestando, ao longo dos anos, a queda do crescimento populacional da faixa etária-alvo da pré-escola (4 e 5 anos) os $10,9 \%$ restantes, em 2014, representam mais de $600 \mathrm{mil}$ crianças à margem do sistema, percentual esse que não deve sofrer alterações significativas até o fim de 2016, prazo estipulado para o cumprimento dos preceitos legais. O quadro se agrava, sobretudo, na região Norte, que apresenta, neste último ano, a menor cobertura do país (80,3\%), com mais de 120 mil crianças não atendidas. Logo a seguir vem a Sul, com taxa de $85,4 \%$. Região campeã de cobertura na pré-escola, o Nordeste praticamente empata com o Sudeste, com índices que perfazem $92,4 \%$ e $91,8 \%$, respectivamente, constituindo-se como as duas únicas regiões que sempre estiveram com linhas de evolução das matrículas acima da média nacional. 
GRÁFICO 1 - Brasil: percentual de crianças de 4 e 5 anos na escola por regiões

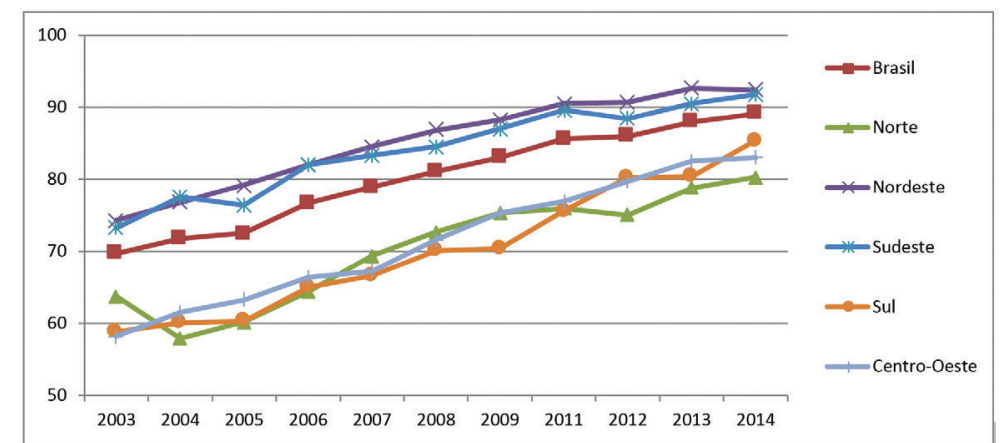

Fonte: Elaboração do autor com base nos dados da Pnad/IBGE, disponibilizados pelo site Observatório do PNE.

Ainda com base no gráfico anterior, ao serem considerados alguns marcadores temporais, traduzidos por determinadas ações no campo das políticas públicas educacionais, torna-se possível realizar algumas inferências. A primeira diz respeito aos resultados do Índice de Desenvolvimento da Educação Básica (Ideb), criado pelo Instituto Nacional de Estudos e Pesquisas Educacionais Anísio Teixeira (Inep), em 2007, que reúne, em um só indicador, dois conceitos de igual importância para a aferição da qualidade da educação no país, quais sejam, fluxo escolar e médias de desempenho. Segundo dados de 2013, avaliando o desempenho de estudantes da $4^{\mathrm{a}}$ série $/ 5^{\circ}$ ano, e ainda que a série histórica $(2005$, 2007, 2009, 2011 e 2013) acene com a melhoria da qualidade do ensino, dentre os dez estados de mais baixo índice de rendimento naquele ano, sete deles, acompanhados nesse triste ranking pelos da região Norte, eram do Nordeste, ocupando seguidamente da terceira à nona colocação: Alagoas, Maranhão, Bahia, Rio Grande do Norte, Sergipe, Paraíba e Piauí. $O$ estado de Pernambuco vinha um pouco à frente, mas na $11^{\text {a }}$ posição, e o do Ceará, em $15^{\circ}$ lugar. Tal constatação nos permite afirmar que, embora a região Nordeste apresente o mais alto percentual de atendimento pré-escolar do país, bem como seja amplamente sabido que a educação escolar é, de fato, elemento facilitador na vida escolar, tal cobertura não vem se traduzindo na melhoria de desempenho de seus estudantes em etapas posteriores. ${ }^{8}$ Essa situação, por

8 Ainda que não tenham correlação direta com o trabalho aqui

apresentado, uma vez que se referem à avaliação de um programa e não de um sistema de cobertura educacional, estudos realizados acerca de um dos principais e mais longevos programas voltados para a infância de crianças pobres nos Estados Unidos, o Head Star, atestam - no que pesem alguns entraves, tais como a falta de articulação com outras políticas de apoio e a não padronização de seu atendimento - impactos positivos, em médio e longo prazos, tanto no desenvolvimento infantil quanto n rendimento escolar futuro de seus beneficiários (BARNETT; HUSTEDT, 2005; GIBBS; LUDWIG; MILLER, 2012). Dessa forma, tal experiência pode se constituir em parâmetro de peso no diálogo com possíveis ações visando ao enfrentamento dessa problemática em nosso país. 
9 Esta última autora, inclusive, faz uma análise bastante interessante de tal paradoxo, quando pondera: "é a região Nordeste a que apresenta melhores taxas. Ora, melhores taxas de frequência à educação infantil no Brasil podem estar associadas a piores indicadores de qualidade na oferta. Por exemplo, a região Nordeste apresenta, ao mesmo tempo, alta cobertura piores indicadores de qualidade, bem como jornada escolar mais curta" (ROSEMBERG, 2014, p. 754).

10 vale esclarecer que, até 2006, vigorava outra política de financiamento educacional, o Fundo de Manutenção e Desenvolvimento do Ensino Fundamental e de Valorização do Magistério (Fundef), que, com base no número de alunos informado no censo escolar. direcionava verbas exclusivamente para o ensino fundamental. A partir da implementação nacional do Fundeb, os alunos matriculados em todas as etapas da educação básica (desde a creche, passando pela pré-escola e o ensino fundamental, até o ensino médio) passaram a contar per capita para o recebimento, por suas respectivas redes, dos recursos constitucionalmente vinculados ao Fundo. sua vez, parece remeter à questão da qualidade da educação oferecida em nosso país, ensejando várias e importantes pesquisas, capazes de desvelar os pontos de estrangulamento desse processo marcadamente perverso, e que deem prosseguimento a outros estudos - tais como os de Maria Malta Campos (2013) e Fúlvia Rosemberg (2014) - acerca do assunto. ${ }^{9}$

Outra situação que fica flagrantemente expressa nos números do Gráfico 1 é que a entrada em vigor, a partir de 2007, do Fundo de Manutenção e Desenvolvimento da Educação Básica e de Valorização dos Profissionais da Educação (Fundeb) (BRASIL, 2007) não se constitui um marcador de peso na esfera pré-escolar. ${ }^{10}$ Isso porque, conforme demonstra o gráfico em tela, sua implementação nacional em pouco ou nada impactou, no sentido de um incremento do ritmo das matrículas na pré-escola mais acentuado do que aquele que caracteriza historicamente o período.

Por sua vez, ainda que tenhamos elementos reduzidos e não definitivos para fazer afirmações mais taxativas, os dados disponíveis deixam antever que, até o ano em tela (2014), o crescimento das matrículas na educação pré-escolar parece não ter sido alterado significativamente por conta da legislação educacional, determinando que as redes municipais de educação universalizem a cobertura até 2016.

A representação gráfica relativa à localidade de atendimento (Gráfico 2) é aquela que atesta um dos saltos mais representativos no período investigado, passando, na área rural, de 53,4\%, em 2003, para quase 85\%, em 2014; ou seja, acumulando um avanço de mais de 30 pontos percentuais e reforçando a trajetória de afunilamento para o alto das variáveis visitadas, fenômeno esse que também é claramente percebido no Gráfico 4 (renda familiar), a ser posteriormente analisado. 
GRÁFICO 2 - Brasil: percentual de crianças de 4 e 5 anos na escola por localidade

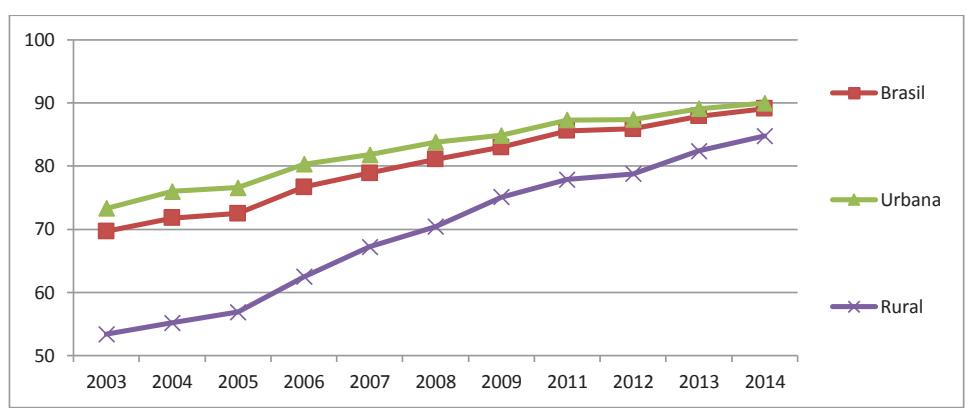

Fonte: Elaboração do autor com base nos dados da Pnad/IBGE, disponibilizados pelo site Observatório do PNE.

Sem dúvida, o terceiro gráfico dessa série é o que apresenta as menores oscilações das distâncias e proximidades entre as variáveis analisadas. Embora também se perceba aqui uma tendência ascendente de inclusão ao longo dos anos, esta ocorre sem que praticamente se operem mudanças significativas nas posições iniciais. Assim, se em 2003 temos os brancos como a população mais atendida $(71,8 \%)$, seguida bem de perto por pretos (68\%) e pardos (67,8\%), em 2014, tais posições se mantêm com cerca de 20 pontos de acréscimo em todas as variáveis, atingindo: $91,3 \%$ de brancos, 87,2 de pretos e $87,5 \%$ de pardos. Tais números, conjugados aos do Gráfico 4, permitem inferir que houve elevação no atendimento das três variáveis de raça/cor provenientes dos estratos sociais de menor poder aquisitivo. Ainda assim, é sempre oportuno lembrar a brilhante análise de Rosemberg sobre o assunto, quando a autora desvela um pouco mais a aparente homogeneidade de tal cobertura, associando a discussão do racismo institucional ao campo das políticas universalistas:

O hiato racial no acesso à educação infantil é reduzido, por vezes inexistente, e em alguns casos a taxa de frequência de crianças negras é até superior à das brancas. A política de educação infantil brasileira sustenta e provoca desigualdade racial? Com certeza. Via discriminação específica contra crianças negras? Considero que não: via desigualdades regionais, via desigualdades econômicas, via desigualdades de gênero e, sobretudo, via desigualdades de idade. Isto é, a penalização de crianças pequenas 
negras, de bebês negros ocorre pelas chamadas políticas universalistas. Esse modelo de educação infantil implantado no Brasil é, de fato, universalista? Com certeza, não! É discriminatório contra as crianças pequenas, particularmente contra bebês, pobres, brancos ou negros. Com certeza contribui para a manutenção da pobreza negra, dos baixos indicadores educacionais de crianças negras. (ROSEMBERG, 2014, p. 754)

GRÁFICO 3 - Brasil: percentual de crianças de 4 e 5 anos na escola por raça/cor

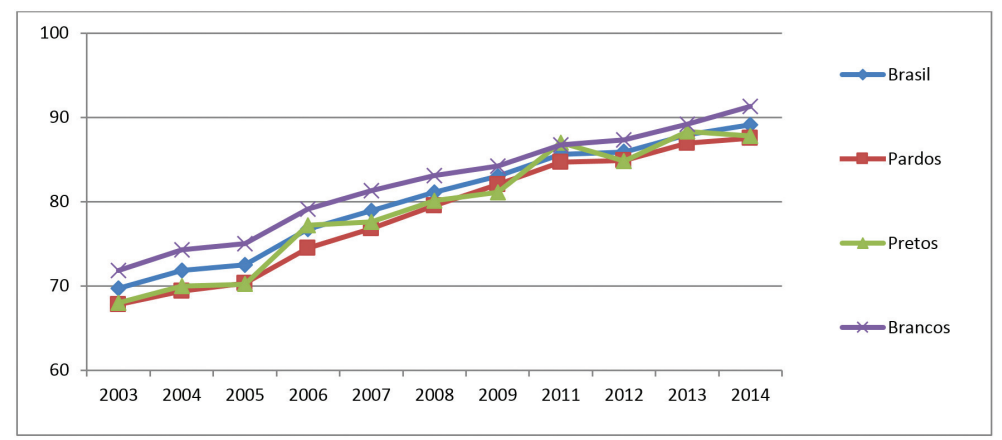

Fonte: Elaboração do autor com base nos dados da Pnad/IBGE, disponibilizados pelo site Observatório do PNE.

Como já era de se esperar, e a exemplo do que ocorre em outros segmentos da educação, é o grupo dos $25 \%$ mais ricos do país que lidera o ranking das taxas de cobertura pré-escolar. Nesse segmento, o atendimento encontra-se praticamente universalizado (96,8\%), situação que despenca mais de dez pontos percentuais quando se trata da condição dos $25 \%$ mais pobres (86,3\%). Entretanto, se comparamos, no Gráfico 4, a evolução percentual do conjunto da população, percebemos um acentuado afunilamento nos anos finais, denotando um avanço bastante significativo por parte de seus setores mais pobres, com perspectiva, inclusive, de um maior estreitamento futuro. Tomando por exemplos, mais uma vez, os segmentos opostos em nossa representação gráfica $(25 \%$ mais ricos e $25 \%$ mais pobres), percebemos que as diferenças no atendimento diminuem cerca de 20 pontos percentuais para esses últimos no período analisado, situação que permite afirmar que, no campo da educação pré-escolar, a era 
de governo do Partido dos Trabalhadores (PT) foi, de fato, para os segmentos mais pobres, um período de inclusão (THEODORO, 2013).

GRÁFICO 4 - Brasil: percentual de crianças de 4 e 5 anos na escola por renda familiar

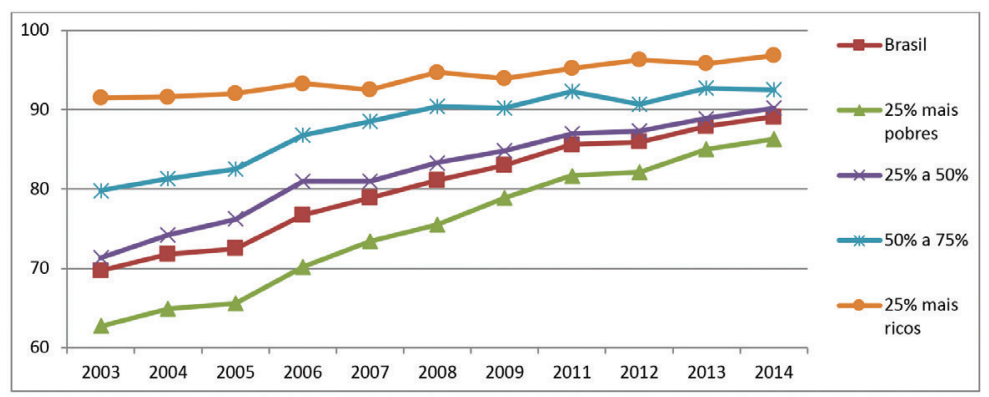

Fonte: Elaboração do autor com base nos dados da Pnad/IBGE, disponibilizados pelo site Observatório do PNE.

\section{DADOS REGIONAIS}

As tabelas e os gráficos adiante são representativos da oferta de educação pré-escolar nas cinco regiões do país, no período de 2003 a 2014, trabalhados das seguintes formas: agrupando, em tabelas, os dados concernentes aos números de matrículas nos estados que compõem a respectiva região; apresentando, em gráficos distintos, variáveis relativas à localidade, raça/cor e renda familiar das crianças atendidas.

Com exceção apenas do ano de 2003, quando perde para a região Sul, a Norte (Tabela 1) é a que apresenta, na série histórica aqui delimitada, o mais baixo percentual de atendimento pré-escolar no país, sendo a que também comporta, em 2014, os três estados que mais se caracterizam por essa triste condição, encabeçados, em ordem crescente, pelo Amapá, com 70\% e uma trajetória absolutamente irregular, Acre, com 73,3\%, e Amazonas, com 74,4\%, todos abaixo do índice regional aferido naquele ano. Observa-se, ainda, uma queda geral na matrícula em todos os estados no ano de 2004, com recuperação em 2006, a partir de quando alguns deles assumem trajetórias oscilantes que certamente apontam a necessidade de estudos mais aprofundados, capazes de esclarecê-las. O estado líder no atendimento regional em quase todo o período é o de Roraima (com Ideb de 5.2, 
em 2013, situando-o na décima posição no ranking geral), o qual, em 2014, atinge sua melhor marca $(89,9 \%)$, mas que representa, entretanto, menos de 1 ponto percentual acima da média nacional.

TABELA 1 - Região Norte: percentual de crianças de 4 e 5 anos na escola por estados

\begin{tabular}{l|c|c|c|c|c|c|c|c|c|c|c}
\hline Rondônia & 53,0 & 44,7 & 47,2 & 51,3 & 53,0 & 54,7 & 63,6 & 59,3 & 67,9 & 69,7 & 83,8 \\
\hline Acre & 61,3 & 55,4 & 50,3 & 53,3 & 60,8 & 62,0 & 64,6 & 79,1 & 64,4 & 69,6 & 73,4 \\
\hline Amazonas & 57,0 & 54,5 & 57,6 & 63,8 & 72,9 & 74,6 & 69,7 & 70,0 & 71,7 & 75,9 & 74,4 \\
\hline Roraima & 75,9 & 65,3 & 73,1 & 81,4 & 81,4 & 85,9 & 84,1 & 80,9 & 77,3 & 82,1 & 89,9 \\
\hline Pará & 70,9 & 63,5 & 63,8 & 66,2 & 71,9 & 75,2 & 81,3 & 81,6 & 78,4 & 82,3 & 83,7 \\
\hline Amapá & 61,4 & 53,6 & 61,9 & 66,5 & 57,3 & 70,9 & 62,7 & 73,6 & 63,7 & 77,1 & 70,0 \\
\hline Tocantins & 58,6 & 51,6 & 62,7 & 68,8 & 71,9 & 73,1 & 75,5 & 75,2 & 83,3 & 81,3 & 80,6 \\
\hline Média Norte & 63,8 & 57,9 & 60,2 & 64,4 & 69,4 & 72,7 & 75,3 & 75,9 & 75,0 & 78,8 & 80,3 \\
\hline
\end{tabular}

Fonte: Elaboração do autor com base nos dados da Pnad/IBGE, disponibilizados pelo site Observatório do PNE.

Ao reagruparmos os dados gerais da região Norte por localidade, raça/cor e renda familiar (gráficos 5, 6 e 7), percebemos algumas variações desses índices, quando comparados aos nacionais. Isso porque, se os últimos se caracterizam por uma trajetória preponderantemente ascendente e linear, os nortistas, ainda que também ascendentes em sua maioria, apresentam trajetórias bastante acidentadas quando confrontadas com as demais, com notáveis avanços e recuos, sobretudo no que diz respeito às questões de raça/cor e localidade. Embora os dados relativos a essa última variável não tenham sido disponibilizados no ano de 2003, percebe-se, pelos demais anos, que a questão rural se impõe como uma das maiores dificuldades da inclusão educacional na região, certamente por conta das já conhecidas grandes distâncias e inúmeras dificuldades de acesso, na qual o transporte fluvial tem lugar de destaque. Tal índice chega a apresentar, em 2005, a terceira mais baixa percentagem de cobertura escolar dentre a totalidade das observadas neste estudo (43,5\%), persistindo como a mais baixa da região até $2014: 72,7 \%$. Nesse mesmo ano, e a exemplo do que se observa de modo praticamente idêntico nas demais regiões, faz-se acompanhar, em sua trajetória histórica, quase sempre e bem de perto, por duas outras variáveis 
associadas à pobreza, quais sejam, a de raça/cor preta - que apresenta aqui a mais baixa taxa de atendimento a esse segmento verificada em todo o estudo $(74,1 \%)$ - e a de menor rendimento familiar, abarcando apenas $77,6 \%$ dos sujeitos nessa condição. Como índices de maior alcance da cobertura pré-escolar na região, destacam-se a faixa dos $25 \%$ mais ricos $(87,4 \%)$, ainda que em rota declinante desde 2011, e a área urbana, que cobre, em 2014, cerca de 83\% de sua população-alvo.

GRÁFICO 5 - Norte: percentual de crianças de 4 e 5 anos na escola por localidade

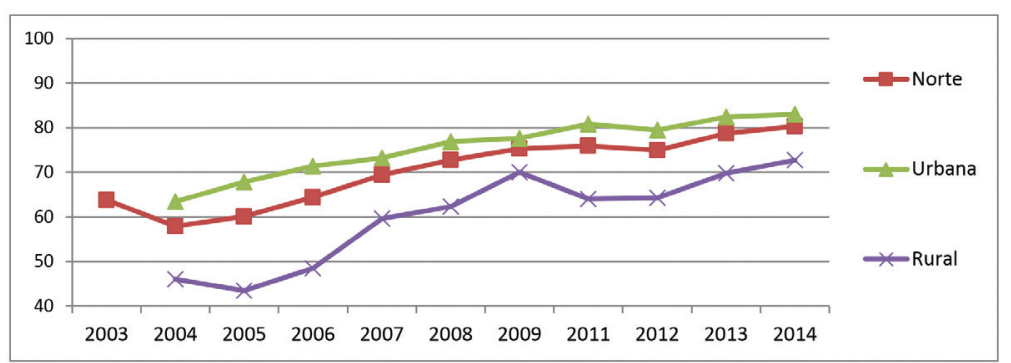

GRÁFICO 6 - Norte: percentual de crianças de 4 e 5 anos na escola por raça/cor

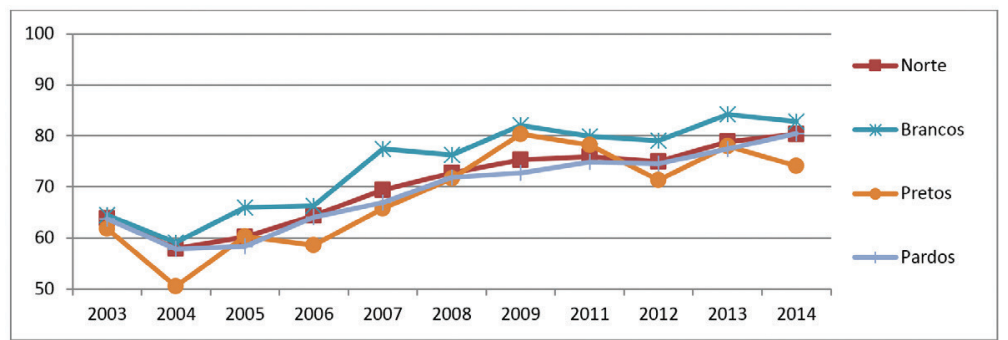

GRÁFICO 7 - Norte: percentual de crianças de 4 e 5 anos na escola por renda familiar

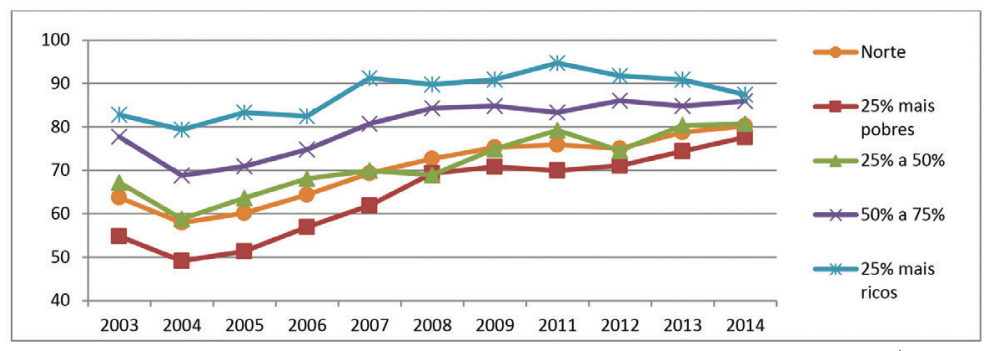

Fonte dos gráficos 5, 6 e 7: Elaboração do autor com base nos dados da Pnad/IBGE, disponibilizados pelo site Observatório do PNE. 
Outra tabela bastante interessante (Tabela 2), por compilar um maior número de elementos, mas também bastante irregular, diz respeito à da região Nordeste. Esta, ressalvando apenas o ano de 2004 da série histórica, lidera o ranking de mais ampla cobertura da pré-escola no Brasil e abriga, em 2014, os quatro estados campeões desse atendimento (Ceará, Piauí, Maranhão e Paraíba), no que pese o fato de todas as suas unidades federadas se encontrarem entre aquelas de mais baixo Índice de Desenvolvimento Humano (IDH) do país, além do baixo posicionamento no Ideb, como já visto. De modo geral, percebe-se que os estados do Ceará e Alagoas apresentam, em 2014, posições divergentes na região: o primeiro, por possuir a melhor marca de atendimento recente no país, 97,3\%, seguido bem perto pelo Piauí (96,6\%), ambos com cobertura praticamente universalizada; e o segundo, Alagoas (que desenha um histórico visivelmente irregular, experimentando saltos e recuos notáveis), por apresentar a menor cobertura $(87,5 \%)$ e os piores IDH e Ideb da região, mas que, ainda assim, situa-se em menos de dois pontos abaixo da média geral e é superior, por exemplo e com exceção de Roraima, à taxa dos demais estados da região Norte, sua vizinha. Vale destacar que, além de Alagoas, em 2014, abaixo da média regional encontram-se também os estados do Rio Grande do Norte, Pernambuco, Bahia e Sergipe.

TABELA 2 - Nordeste: percentual de crianças de 4 e 5 anos na escola por estados

\begin{tabular}{l|c|c|c|c|c|c|c|c|c|c|c}
\hline Maranhão & 74,1 & 77,2 & 77,1 & 79,2 & 85,3 & 90,4 & 90,9 & 93,5 & 91,7 & 92,7 & 93,8 \\
\hline Piauí & 72,8 & 80,7 & 78,5 & 80,0 & 79,1 & 89,8 & 92,7 & 95,5 & 92,7 & 96,8 & 96,6 \\
\hline Ceará & 83,0 & 85,0 & 88,4 & 89,3 & 91,1 & 91,5 & 94,8 & 92,6 & 95,0 & 96,8 & 97,3 \\
\hline Rio Grande do Norte & 77,4 & 85,2 & 83,0 & 90,0 & 90,5 & 89,8 & 86,1 & 89,6 & 93,9 & 92,5 & 89,2 \\
\hline Paraíba & 79,5 & 73,7 & 83,8 & 84,9 & 86,6 & 87,4 & 88,8 & 88,9 & 89,1 & 95,1 & 93,4 \\
\hline Pernambuco & 71,3 & 71,7 & 75,5 & 80,9 & 81,5 & 85,6 & 83,1 & 87,2 & 90,5 & 88,0 & 90,2 \\
\hline Alagoas & 61,0 & 68,5 & 68,2 & 71,4 & 79,1 & 71,9 & 79,7 & 85,6 & 84,6 & 83,7 & 87,5 \\
\hline Sergipe & 80,7 & 79,4 & 78,7 & 83,6 & 84,2 & 85,1 & 89,1 & 92,5 & 95,3 & 96,2 & 91,8 \\
\hline Bahia & 71,6 & 74,5 & 78,1 & 80,3 & 82,6 & 85,7 & 87,6 & 89,6 & 87,5 & 92,7 & 90,7 \\
\hline Média Nordeste & 74,3 & 76,8 & 79,2 & 82,0 & 84,5 & 86,8 & 88,2 & 90,5 & 90,7 & 92,6 & 92,4 \\
\hline
\end{tabular}

Fonte: Elaboração do autor com base nos dados da Pnad/IBGE, disponibilizados pelo site Observatório do PNE. 
Os gráficos 8, 9 e 10 revelam mais características educacionais do Nordeste. Assim, fica claro que a parcela dos $25 \%$ mais pobres foi a que teve os menores índices de cobertura regional nos dois últimos anos, embora tenha desenhado, ao longo de todo o período, juntamente com a variável rural (esta com uma recuperação ainda mais visível, equiparando-se exatamente com a urbana, em 2014: 92,4\%), as linhas mais expressivas no que diz respeito à ampliação do atendimento. Como também fica latente, na outra ponta, a inclusão vivenciada pelas parcelas com a renda mais elevada $-25 \%$ mais ricos e $50 \%$ a $75 \%$ - liderou esse ranking, praticamente universalizando seu atendimento, com percentuais de 98,9\% e $96,8 \%$, respectivamente. Digna de registro é também a expressiva cobertura conquistada pelas três categorias de raça/ cor, praticamente empatadas, desde 2013, acima dos 90 pontos percentuais, sobretudo a das crianças pretas, que, no período, avança 23 pontos, numa trajetória bastante provável de universalização nos próximos anos. A conferir.

GRÁFICO 8 - Nordeste: percentual de crianças de 4 e 5 anos na escola por localidade

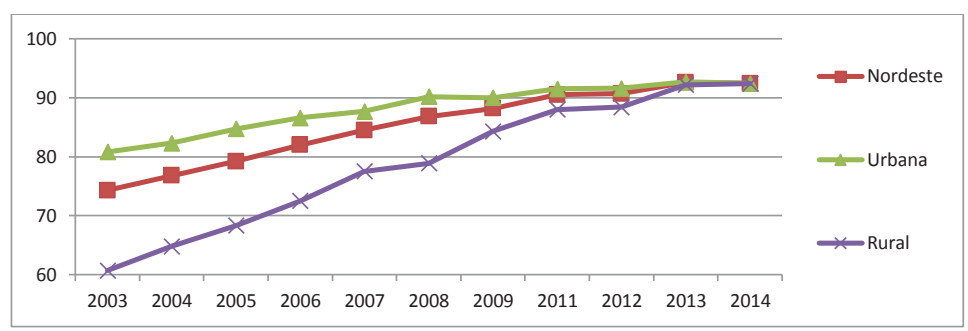

GRÁFICO 9 - Nordeste: percentual de crianças de 4 e 5 anos na escola por raça/cor

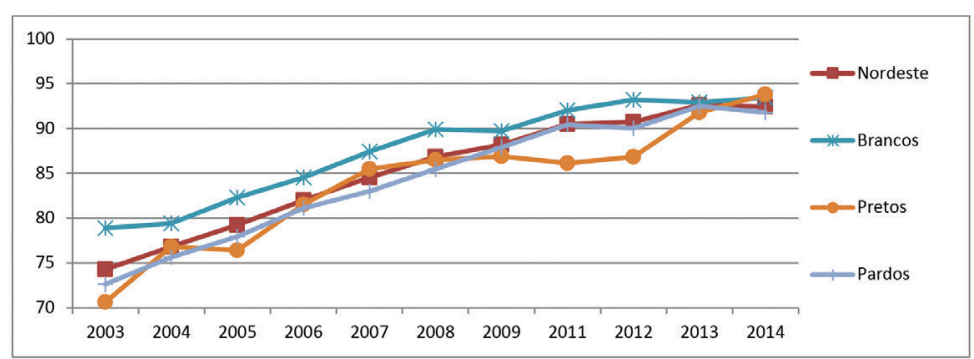


GRÁFICO 10 - Nordeste: percentual de crianças de 4 e 5 anos na escola por renda familiar

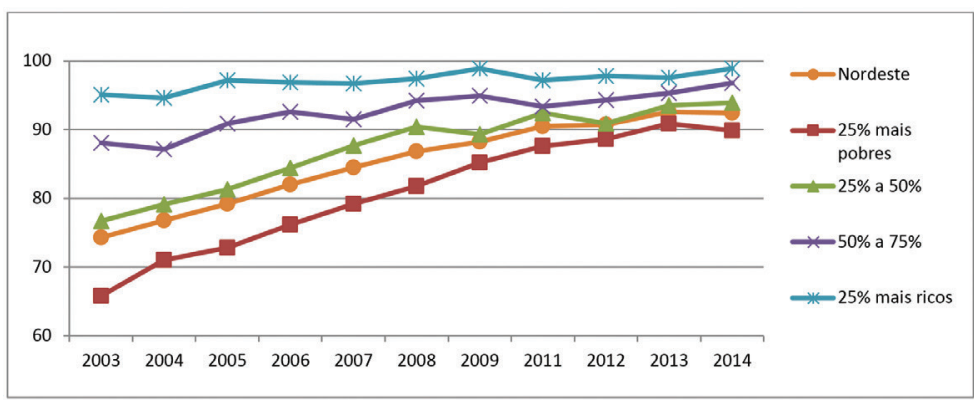

Fonte dos gráficos 8, 9 e 10: Elaboração do autor com base nos dados da Pnad/IBGE, disponibilizados pelo site Observatório do PNE.

A região Sudeste e seus estados são alvo da análise dos dados constantes da Tabela 3. De modo geral, salta aos olhos a recuperação de Minas Gerais e do Espírito Santo (este, porém, com um percurso mais acidentado) na ampliação da cobertura da educação pré-escolar ao longo dos anos, notadamente pela magnitude dos saltos observados - no que pese um recuo de ambos em 2005 - de mais de 23 pontos percentuais. Ainda que Minas Gerais permaneça, no período - salvo em 2004 -, como a unidade de menor índice de atendimento da região, em 2014, acumula um ponto percentual acima da média nacional e apresenta, segundo o Ideb/2013, o segundo melhor desempenho do país nas quatro primeiras séries do ensino fundamental. O Rio de Janeiro é o de maior cobertura no início do marco temporal (81,3\%), declinando, entretanto, até assumir a penúltima posição em 2014 (90,4\%). Na região, o estado de São Paulo lidera a cobertura tanto na pré-escola, alcançando 93,1\% em 2014, quanto no Ideb/2013 nacional. Vale destacar que, em 2014, a região Sudeste é aquela em que as distâncias entre as coberturas da pré-escola entre os estados são as mais curtas, denotando uma relativa homogeneidade. 
TABELA 3 - Sudeste: percentual de crianças de 4 e 5 anos na escola por estados

\begin{tabular}{l|c|c|c|c|c|c|c|c|c|c|c}
\hline Minas Gerais & 66,9 & 73,6 & 70,3 & 74,3 & 77,5 & 81,2 & 82,5 & 85,8 & 88,1 & 88,7 & 90,1 \\
\hline Espírito Santo & 67,3 & 73,0 & 71,5 & 83,6 & 79,4 & 82,7 & 83,2 & 90,3 & 93,3 & 91,2 & 92,4 \\
\hline Rio de Janeiro & 81,3 & 83,8 & 80,6 & 85,7 & 83,5 & 86,7 & 86,2 & 88,6 & 88,1 & 89,8 & 90,4 \\
\hline São Paulo & 73,8 & 77,7 & 78,4 & 84,6 & 86,7 & 85,6 & 89,8 & 91,8 & 88,2 & 91,4 & 93,1 \\
\hline Média Sudeste & 73,2 & 77,5 & 76,4 & 82,0 & 83,3 & 84,5 & 87,0 & 89,6 & 88,4 & 90,5 & 91,8 \\
\hline
\end{tabular}

Fonte: Elaboração do autor com base nos dados da Pnad/IBGE, disponibilizados pelo site Observatório do PNE.

Repetindo a problemática tanto da região Norte quanto da Centro-Oeste, como veremos mais adiante, a questão rural é a que se caracteriza, na Sudeste, como a mais difícil, traduzida por apresentar a menor cobertura em todo o período revisto. Entretanto, ainda que parta do mais baixo patamar de atendimento registrado entre todas as regiões no ano de 2003, $48,3 \%$ (lembrando que não existe registro desse ano na região Norte), e atinja 80,5\% em 2014, é expressivo o salto de mais de $30 \%$ alcançado, ainda que marcado por uma trajetória ziguezagueante (Gráfico 11). A seguir, na penúltima colocação, está a inclusão da raça/cor preta, cuja cobertura encampa apenas 87\% dos sujeitos, numa trajetória temporal também bastante acidentada, a exemplo do que acontece em quase todas as regiões (Gráfico 12). Na outra ponta, entre os $25 \%$ mais ricos, é que se dá a mais expressiva cobertura regional do período, praticamente universalizada, chegando a atingir $99,1 \% \mathrm{em}$ 2012 e se aproximando, em 2014 (96,7\%), tanto da cobertura da população de renda familiar de $50 \%$ a $75 \%$ (94,3\%) quanto do atendimento da faixa de $25 \%$ a $50 \%$ (94\%). Partindo da constatação de que o estrato dos $25 \%$ mais pobres já apresenta cobertura equivalente à da média nacional (89\%), pode-se dizer que é nessa região que se verificam as menores disparidades no acesso quando considerada a renda familiar. 
GRÁFICO 11 - Sudeste: percentual de crianças de 4 e 5 anos na escola por localidade

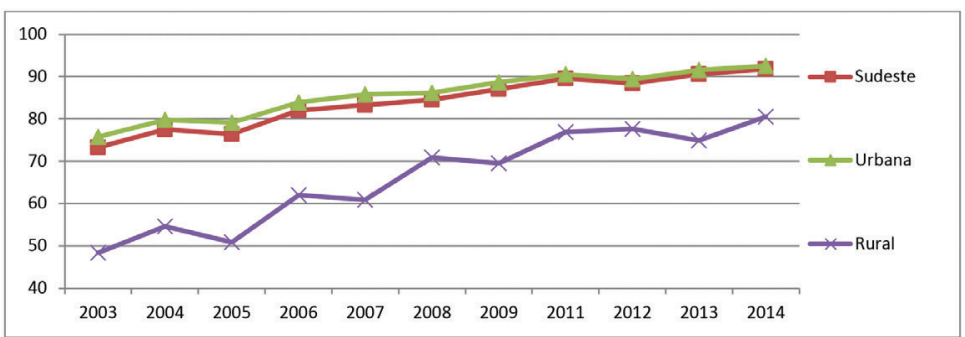

GRÁFICO 12 - Sudeste: percentual de crianças de 4 e 5 anos na escola por raça/cor

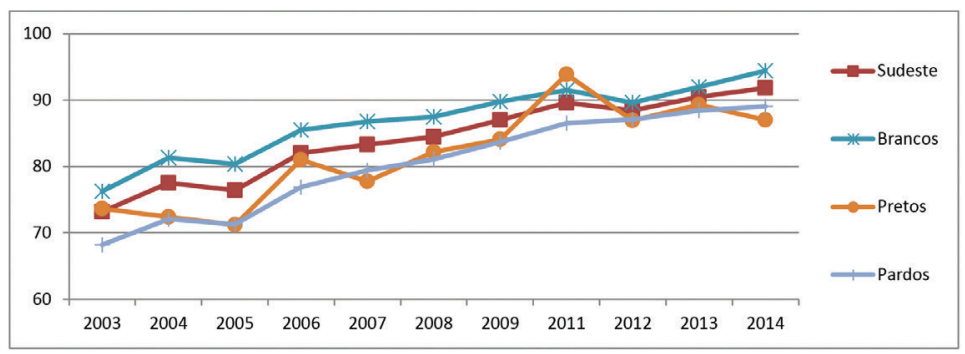

GRÁFICO 13 - Sudeste: percentual de crianças de 4 e 5 anos na escola por renda familiar

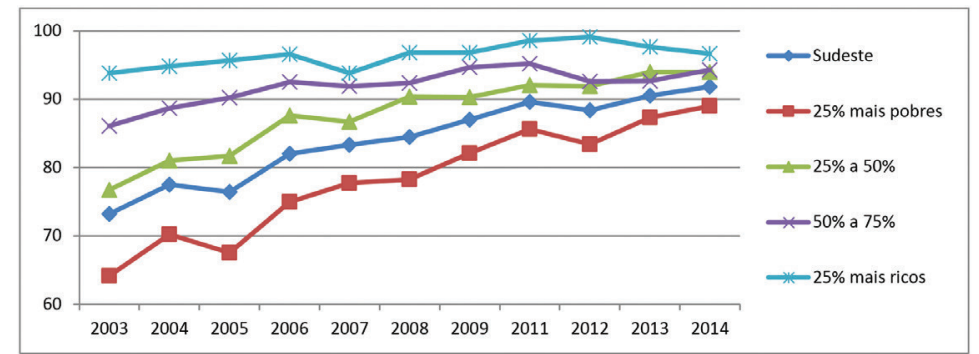

Fonte dos gráficos 11, 12 e 13: Elaboração do autor com base nos dados da Pnad/IBGE, disponibilizados pelo site Observatório do PNE.

A Tabela 4 aborda a região Sul e seus estados. Embora seja a segunda com mais alto IDH do país, bem como suas unidades federadas estejam entre as que possuem o mais alto Ideb, no que tange ao atendimento pré-escolar, como já pontuado, só perde em baixo índice de cobertura para a região Norte $(85,4 \%$ contra $80,3 \%$, respectivamente), o que indica a pertinência de estudos sobre o fenômeno. Desagregando os dados, temos Santa Catarina como o estado líder em todo o período, atingindo, em $2014,89,9 \%$ da cobertura 
(pouco acima, portanto, da média nacional), e, na outra ponta, o Rio Grande do Sul, com a inclusão de apenas 80,1\% dessas crianças.

TABELA 4 - Sul: percentual de crianças de 4 e 5 anos na escola por estados

\begin{tabular}{l|c|c|c|c|c|c|c|c|c|c|c}
\hline Paraná & 64,0 & 62,7 & 64,4 & 65,5 & 73,6 & 74,6 & 74,1 & 77,7 & 82,3 & 85,1 & 87,5 \\
\hline Santa Catarina & 71,5 & 73,2 & 77,7 & 85,8 & 78,0 & 82,5 & 79,4 & 82,5 & 89,2 & 87,8 & 89,9 \\
\hline Rio Grande do Sul & 45,7 & 50,1 & 46,7 & 54,2 & 52,6 & 58,1 & 61,1 & 69,5 & 72,3 & 70,6 & 80,1 \\
\hline Média Sul & 58,8 & 60,1 & 60,3 & 65,0 & 66,6 & 70,1 & 70,4 & 75,6 & 80,2 & 80,4 & 85,4 \\
\hline
\end{tabular}

Fonte: Elaboração do autor com base nos dados da Pnad/IBGE, disponibilizados pelo site Observatório do PNE.

Ao desagregarmos os dados pelas demais variáveis aqui observadas, temos alguns índices bastante interessantes. O primeiro diz respeito à rápida recuperação da cobertura oferecida na área rural, que salta, em 2004 , de $37,4 \%$ (porcentagem esta que é a segunda mais baixa verificada no conjunto de todas as demais aferidas neste estudo) para $84,1 \%$, em 2014, com clara tendência de alta (Gráfico 14) e praticamente se equiparando à área urbana $(85,6 \%)$. Outro ponto interessante - e a exemplo de outras regiões, notadamente a Norte - concerne à repetição da trajetória ziguezagueante de inclusão de crianças pretas, cuja acentuada queda e posterior recuperação entre 2008 e 2009 (de 62,5\% para 49,5\%) merece aprofundamento (Gráfico 15). Em 2014, os pardos juntam-se aos $25 \%$ mais pobres dentre os que apresentam os mais baixos índices de atendimento, 78,6\% e 79,9\%, respectivamente, enquanto os $25 \%$ mais ricos repetem a trajetória verificada nas demais regiões, sempre pelo alto, mas aqui levemente oscilante, com sua cobertura praticamente universalizada (Gráfico 16). Note-se, por fim, que essa região apresenta a segunda maior disparidade entre a cobertura prestada aos $25 \%$ mais ricos e aos $25 \%$ mais pobres $(97,9 \%$ e $79,9 \%$, respectivamente), ficando atrás apenas da Centro-Oeste, conforme veremos a seguir. 
GRÁFICO 14 - Sul: percentual de crianças de 4 e 5 anos na escola por localidade

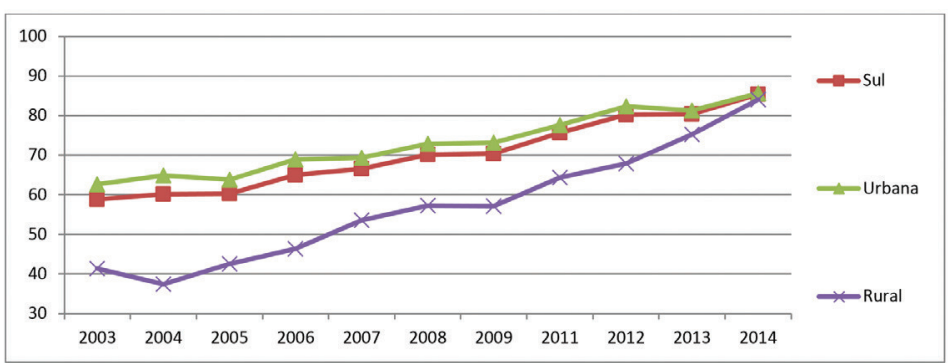

GRÁFICO 15 - Sul: percentual de crianças de 4 e 5 anos na escola por raça/cor

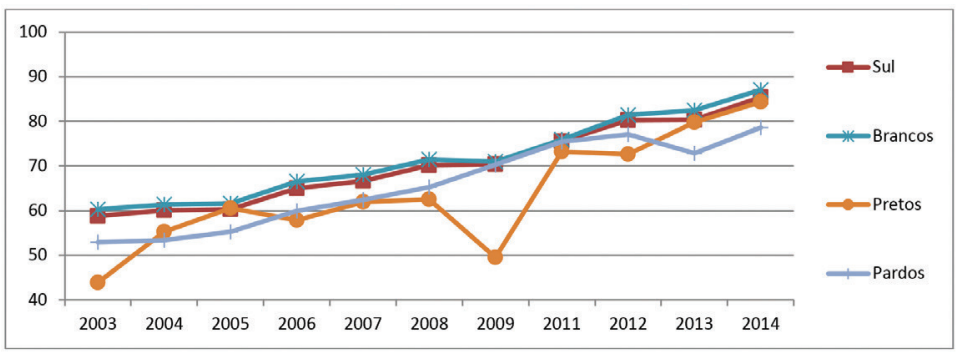

GRÁFICO 16 - Sul: percentual de crianças de 4 e 5 anos na escola por renda familiar

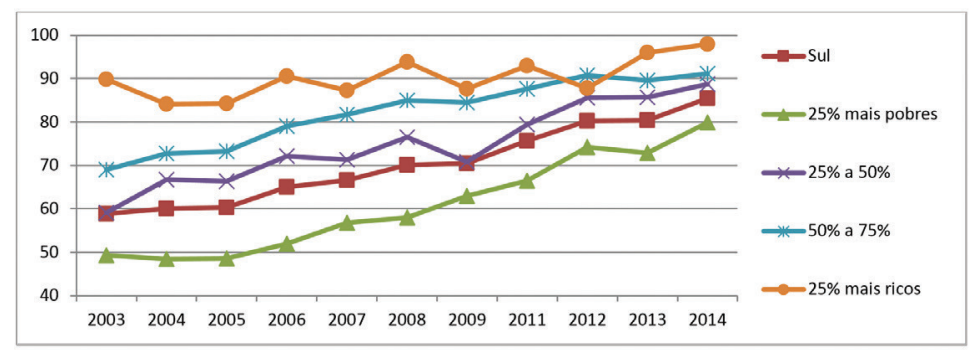

Fonte dos gráficos 14, 15 e 16: Elaboração do autor com base nos dados da Pnad/IBGE, disponibilizados pelo site Observatório do PNE.

Última das regiões brasileiras a ser aqui analisada, o Centro-Oeste ilustra, na Tabela 5, um quadro bastante similar ao encontrado no Sudeste (ainda que apresente taxas bem mais modestas de cobertura do que este último); vale destacar, no entanto, que absolutamente todos os seus percentuais de cobertura se encontram abaixo da média nacional. De imediato, salta aos olhos a trajetória de Mato Grosso do Sul (12 colocação no Ideb/2013) como o mais alto índice da região, 
avançando de $47,8 \%$, em 2003 , para $88,8 \%$, em 2014 , ou seja, mais de 40 pontos percentuais. Na outra ponta, encontra-se Goiás (sexta colocação no Ideb/2013), unidade que apresenta, na série histórica, no geral, a cobertura mais tímida, atendendo a apenas $80 \%$ da demanda potencial de crianças de 4 e 5 anos em 2014. No mais, destaca-se a liderança do Distrito Federal no período, unidade da federação que alcança o IDH municipal mais elevado do país $(0,824)$ e o quinto lugar no Ideb/2013, à frente dos demais estados em dez dos 12 anos do período aqui tratado.

TABELA 5 - Região Centro-Oeste: percentual de crianças de 4 e 5 anos na escola por estados e Distrito Federal

\begin{tabular}{l|c|c|c|c|c|c|c|c|c|c|c}
\hline Mato Grosso do Sul & 47,8 & 54,8 & 64,1 & 63,6 & 68,8 & 76,3 & 79,4 & 79,6 & 78,7 & 84,9 & 88,8 \\
\hline Mato Grosso & 58,6 & 60,5 & 59,0 & 68,2 & 60,0 & 61,7 & 75,7 & 83,3 & 79,5 & 80,3 & 84,1 \\
\hline Goiás & 59,2 & 60,3 & 59,1 & 62,1 & 65,4 & 69,1 & 69,3 & 71,5 & 78,0 & 81,0 & 80,0 \\
\hline Distrito Federal & 65,3 & 71,3 & 76,2 & 76,5 & 77,5 & 85,6 & 86,1 & 79,1 & 84,5 & 86,6 & 82,7 \\
\hline Média CO & 58,2 & 61,5 & 63,2 & 66,4 & 67,2 & 71,6 & 75,3 & 76,9 & 79,7 & 82,5 & 83,0 \\
\hline
\end{tabular}

Fonte: Elaboração do autor com base nos dados da Pnad/IBGE, disponibilizados pelo site Observatório do PNE.

Desagregando os dados (gráficos 17, 18 e 19), nota-se que a região Centro-Oeste repete os padrões observados em grande parte das regiões brasileiras, com atendimento praticamente universal da população dos estratos mais ricos, bem como, na outra mão, baixa cobertura na localidade rural, ainda que, a exemplo da maioria dos outros indicadores, suas linhas, embora oscilantes, apresentem tendência ascendente. Além do baixíssimo atendimento na área rural, como já referido (que apresenta, em 2003, a menor porcentagem de cobertura escolar dentre a totalidade daquelas observadas neste estudo: $34,4 \%$ ), tal oscilação se manifesta, também e notadamente, na cobertura da educação pré-escolar das crianças pretas, cuja exígua taxa de $77,5 \%$, em 2014 , praticamente pareada com a dos $25 \%$ mais pobres $(77,7 \%)$, decorre de uma queda de quase sete pontos em relação ao ano anterior, 2013, quando atingiu $83,8 \%$, e aponta a necessidade de estudos mais aprofundados, com vistas a uma melhor compreensão do fenômeno. Vale ainda destacar que, de acordo 
com os dados revistos, a região é a que apresenta a maior diferença entre o atendimento urbano e o rural $(84,9 \%$ contra 63,1\%), como também a maior distância entre o serviço prestado aos $25 \%$ mais ricos e aos $25 \%$ mais pobres $(97,8 \%$ contra $77,7 \%$, respectivamente) no ano de 2014 , o que aponta a necessidade de os governos dessa região - sobretudo os municipais, a quem compete direta e constitucionalmente o atendimento pré-escolar - empreenderem iniciativas urgentes no sentido de enfrentar tais disparidades.

GRÁFICO 17 - Região Centro-Oeste: percentual de crianças de 4 e 5 anos na escola por localidade

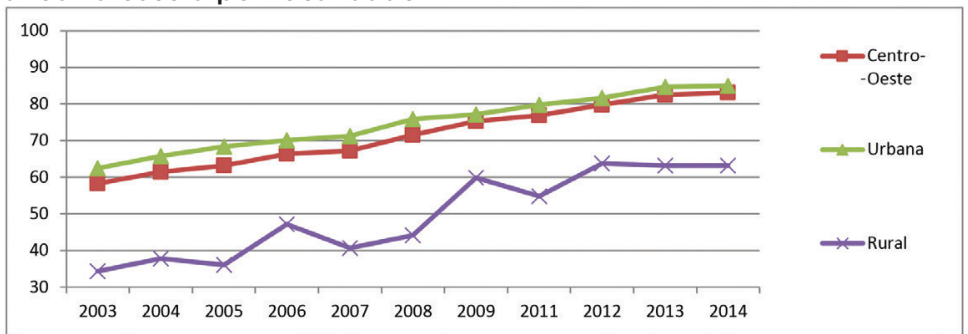

GRÁFICO 18 - Região Centro-Oeste: percentual de crianças de 4 e 5 anos na escola por raça/cor

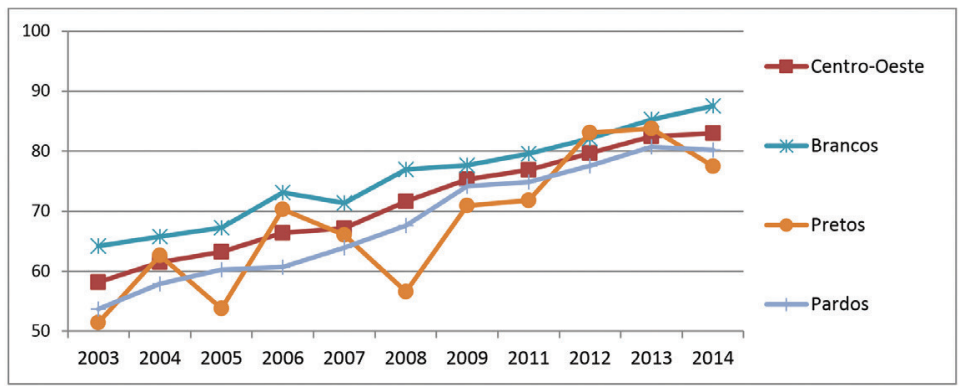


GRÁFICO 19 - Região Centro-Oeste: percentual de crianças de 4 e 5 anos na escola por renda familiar

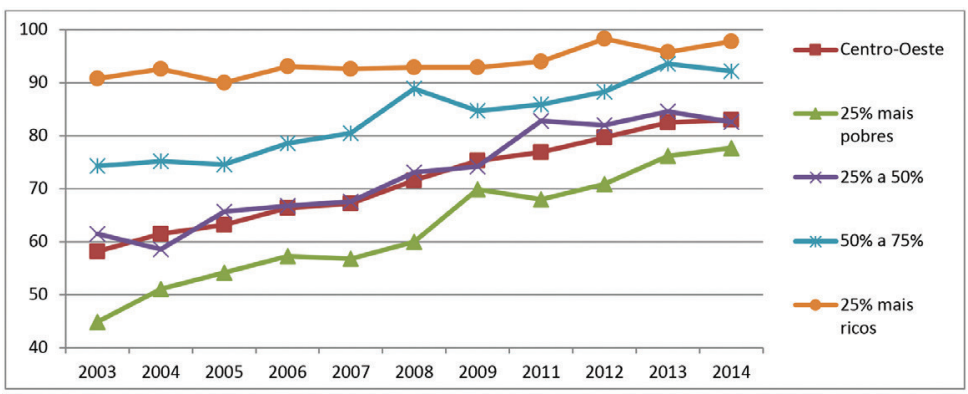

Fonte dos gráficos 17, 18 e 19: Elaboração do autor com base nos dados da Pnad/IBGE, disponibilizados pelo site Observatório do PNE.

\section{ALGUMAS CONCLUSÕES PRELIMINARES}

Conforme exposto no início deste estudo, o objetivo aqui perseguido foi, de forma bastante leve e amparada em números provenientes da Pnad/IBGE, oferecer algumas pistas acerca de como se deu a oferta da pré-escola em nosso país, no período de 2003 a 2014, tendo em vista o arcabouço legal que determina, até o fim do ano de 2016, a sua universalização obrigatória.

Como vimos, com base nos dados aqui sistematizados, temos ainda, em 2014, um déficit de atendimento que exclui mais de 600 mil crianças de 4 e 5 anos da educação pré-escolar, situação que, em termos regionais, expressa-se com mais clareza no Norte do país, especialmente no estado do Amapá. A problemática rural é talvez o mais grave dos entraves que se interpõem a essa universalização, sendo recorrente em todas as regiões brasileiras, notadamente no Centro-Oeste, Norte e Sudeste. Também fica claro que os maiores excluídos dessa etapa educacional são aqueles que, historicamente, experimentaram/experimentam o descaso da maior parte dos governos brasileiros, quer sejam os $25 \%$ mais pobres do Brasil, ainda que tenha sido esse o segmento que apresentou o maior salto no atendimento durante o período visitado. Pertencer à raça/cor preta também é um fator determinante de não atendimento na pré-escola, notadamente nas regiões Centro-Oeste e Norte, estrato populacional que apresenta trajetórias com as linhas mais irregulares, oscilantes, que certamente remetem à necessidade de estudos mais aprofundados acerca do fenômeno. 
11 Ainda que não possam ser gregados aos dados utilizados neste estudo, uma vez que são originários de fonte diferente (Inep) da aqui utilizada (IBGE), apresentando algumas divergências, historicamente não se observam diferenças gritante quanto à magnitude dos números o que permite, diante da realidad de não matrícula de mais de 600 mil crianças de 4 e 5 anos no pais em 2014, realizar as inferências aqu apresentadas.

12 Vale lembrar que devem - ou deveriam - proceder dos royalties da exploração do pré-sal a grande maioria dos recursos a serem injetados na esfera educacional, a fim de que o país se torne capaz de cumprir a meta 20 do PNE, qual seja, a aplicação, até 2024, de pelo menos $10 \%$ do Produto Interno Bruto (PIB) em educação.
Outro ponto importante revelado através dos números disponibilizados diz respeito ao pouquíssimo ou nenhum impacto do Fundeb - instituído em 2007, no sentido de alterar o ritmo progressivo das matrículas da pré-escola, verificado ao longo dos anos aferidos -, e ao aparente efeito nulo nessa trajetória da promulgação da Emenda Constitucional 59/09 e das Leis 12.796/13 e 13.005/14 determinando a oferta universal e obrigatória da pré-escola até 2016. Outra curiosidade deve-se ao fato de que, de acordo com os índices aqui aferidos, uma maior cobertura na educação pré-escolar não determina, por si mesma, um melhor rendimento escolar em etapas posteriores, como acontece com a região Nordeste - campeã no atendimento, mas que ostenta os piores números de qualidade divulgados no Ideb de 2013 -, situação que resvala na questão da qualidade da educação oferecida e aponta novas e profícuas possibilidades de estudos.

De acordo com os dados desvelados, podemos afirmar que estamos em um caminho cuja sinalização óbvia é a de que não atingiremos a meta de universalizar a pré-escola nos termos propostos e dentro do prazo determinado por lei. Reforçam nossa certeza os números divulgados pelo Censo Escolar de 2015, que, por sua vez, atestam um discreto decréscimo na matrícula desse segmento em relação ao ano de 2014 (recuo de 4.923.158 para 4.964.015, respectivamente). ${ }^{11}$

Tal convicção se fortalece ainda mais quando nos deparamos com o fato de o país atravessar um momento de exacerbada instabilidade política, traduzido pelo afastamento, sem amparo constitucional, da representação democraticamente eleita por mais de 54 milhões de votos, após um período de estagnação que perdurou cerca de dois anos, imposto por forças conservadoras oriundas do Congresso Nacional, Senado Federal e Poder Judiciário, entre outras instituições. Essa conjuntura, combinada à baixa internacional do preço do barril de petróleo e de seus derivados, aí incluído o pré-sal ${ }^{12}$ - abalou profundamente a receita fiscal brasileira, de onde provém a maior parte dos recursos destinados à educação, o que, em termos práticos, vem significando a óbvia redução dos investimentos a serem realizados na área. O governo interino "empossado" em maio de 2016 e "legitimado" 
inconstitucionalmente em agosto desse mesmo ano, comprometido, de modo orgânico, com questões econômicas mais diretamente relacionadas aos interesses da esfera empresarial privada do país, embora negue, vem de uma tradição política que não hesita em lançar mão da redução de custos em todas as esferas, inclusive a da educação, a fim de fazer ajustes na economia que pouco ou nada comungam com ideais de fortalecimento, de fato, de uma "cidadania educacional”. Assim, sem verbas adequadas, não há investimento; sem investimento, não há expansão e, muito menos, educação de qualidade.

Diante desse triste cenário, caso não sejam operadas mudanças substanciais nos caminhos aos quais os atuais acontecimentos parecem nos conduzir, podemos ter certeza de que andaremos a passos largos - e mais uma vez em nossa história - para rapidamente transformar em letra-morta várias das históricas conquistas sociais expressas por lei. O que, na prática, representa o sequestro violento do "direito a ter direitos”, sobretudo para as crianças mais pobres, pretas e oriundas das áreas rurais mais afastadas do litoral deste país.

\section{REFERÊNCIAS}

ALVARADO, Lusmidia; GARCÍA, Margarita. Características más relevantes del paradigma sócio-crítico: su aplicación en investigaciones de educación ambiental y de enseñanza de las ciências realizadas en el Doctorado de Educación del Instituto Pedagógico de Caracas. Sapiens: Revista Universitaria de Investigación, Caracas, Año 9, n. 2, p. 187-202, dic. 2008.

BARNETT, Steven; HUSTEDT, Jason. Head Start's lasting benefits. Infants \& Young Children, New York, v. 18, n. 1, p. 16-24, Jan./Mar. 2005.

BRASIL. Congresso Nacional. Lei n. 9394, de 20 de dezembro de 1996. Lei de Diretrizes e Bases da Educação Nacional. Brasília, DF: Senado Federal, 1996.

BRASIL. Congresso Nacional. Lei n. 11.494, de 20 de junho de 2007. Regulamenta o Fundo de Manutenção e Desenvolvimento da Educação Básica e de Valorização dos Profissionais da Educação - FUNDEB -, de que trata o art. 60 do Ato das Disposições Constitucionais Transitórias; altera a Lei no. 10.195, de 14 de fevereiro de 2001; revoga dispositivos das Leis nos. 9.424, de 24 de dezembro de 1996, 10.880, de 9 de junho de 2004, e 10.845, de 5 de março de 2004; e dá outras providências. Brasília, DF, 2007.

BRASIL. Congresso Nacional. Emenda Constitucional n. 59, de 11 de novembro de 2009. Diário Oficial da União, Brasília, DF, 12 nov. 2009. 
BRASIL. Congresso Nacional. Lei n. 12.796, de 04 de abril de 2013. Altera a Lei no. 9.394, de 20 de dezembro de 1996, que estabelece as diretrizes e bases da educação nacional, para dispor sobre a formação dos profissionais da educação e dar outras providências. Brasília, DF: Senado Federal, 2013.

BRASIL. Congresso Nacional. Lei n. 13.005, de 25 de junho de 2014. Aprova o Plano Nacional de Educação 2014-2024 e dá outras providências. Brasília, DF: Senado Federal, 2014.

CAMPOS, Maria Malta. Entre as políticas de qualidade e a qualidade das práticas. Cadernos de Pesquisa, São Paulo, v. 43, n. 148, p. 22-43, jan./abr. 2013.

CAMPOS, Maria Malta; FÜLLGRAF, Jodete; WIGGERS, Verena. Qualidade da educação infantil brasileira: alguns resultados de pesquisa. Cadernos de Pesquisa, São Paulo, v. 36, n. 127, p. 87-128, jan./abr. 2006.

CAMPOS, Rosânia; BARBOSA, Maria Carmen Silveira. Obrigatoriedade de matrícula aos quatro anos: ampliação ou recuo do direito? Textura, Canoas, RS, v. 18, n. 36, p. 66-86, jan./abr. 2016.

CAVALCANTI, Meire; MARANGON, Cristiane. Entre o direito e a obrigação: obrigatoriedade do ensino não é determinante para o aumento das matrículas e para a permanência dos estudantes na escola. Entrevista com Vital Didonet. Revista Educação, São Paulo, 10 set. 2011. Disponível em: $<$ http://www.revistaeducacao.com.br/entre-o-direito-e-a-obrigacao/>. Acesso em: 13 jun. 2016.

CURY, Carlos Roberto Jamil. A educação como desafio na ordem jurídica. In: LOPES, Eliana Marta Teixeira; FARIA FILHO, Luciano Mendes; VEIGA, Cynthia Greive (Org.). 500 anos de educação no Brasil. Belo Horizonte: Autêntica, 2000.

CURY, Carlos Roberto Jamil. A educação básica como direito. Cadernos de Pesquisa, São Paulo, v. 38, n. 134, p. 293-303, maio/ago. 2008.

CURY, Carlos Roberto Jamil; FERREIRA, Luiz Antonio Miguel. Obrigatoriedade da educação das crianças e adolescentes: uma questão de oferta ou de efetivo atendimento? Nuances: estudos sobre educação, Presidente Prudente, SP, v. 17, n. 18, p. 124-145, jan./dez. 2010.

DIDONET, Vital. Dilemas da obrigatoriedade da pré-escola. Pátio: Educação Infantil, Porto Alegre, n. 38, jan. 2014. Disponível em: <http://loja.grupoa. com.br/revista-patio/artigo/10074/dilemas-da-obrigatoriedade-da-pre-escola. aspx>. Acesso em: 29 jun. 2016.

DURHAM, Eunice Ribeiro. A política educacional do governo Fernando Henrique Cardoso: Uma visão comparada. Novos Estudos Cebrap, São Paulo, n. 88, p. 153-179, nov. 2010.

GIBBS, Chloe; LUDWIG, Jens; MILLER, Douglas. Does head start do any lasting good? In: BAILEY, Martha; DANZIGER, Sheldon (Ed.). The war on poverty: a 50-year retrospective. New York: Russell Sage Foundation, 2012.

KAPPEL, Maria Dolores Bombardelli; CARVALHO, Maria Cristina; KRAMER, Sonia. Perfil das crianças de 0 a 6 anos que freqüentam creches, pré-escolas e 
escolas: uma análise dos resultados da Pesquisa sobre Padrões de Vida/IBGE. Revista Brasileira de Educação, Rio de Janeiro, n. 16, p. 35-47, jan./abr. 2001.

OLIVEIRA, Romualdo Portela. Da universalização do ensino fundamental ao desafio da qualidade: uma análise histórica. Educação \& Sociedade, Campinas, SP, v. 28, n. 100 , p. 661-690, out. 2007.

ROSEMBERG, Fúlvia. Expansão da educação infantil e processos de exclusão. Cadernos de Pesquisa, São Paulo, n. 107, p. 7-40, jul. 1999.

ROSEMBERG, Fúlvia. Educação infantil e relações raciais: a tensão entre igualdade e diversidade. Cadernos de Pesquisa, São Paulo, v. 44, n. 153, p. 742-759, jul./set. 2014. Disponível em: <http://www.scielo.br/scielo. php?script=sci_arttext\&pid=S0100-15742014000300013\&lng=en\&nrm=iso $>$. Acesso em: 13 jul. 2016.

SILVA, Lidiane Rodrigues Campêlo da et al. Pesquisa documental: alternativa investigativa na formação docente. In: CONGRESSO NACIONAL DE EDUCAÇÃO, 9.; ENCONTRO SUL BRASILEIRO DE PSICOPEDAGOGIA, 3., 26 a 29 out. 2009, Curitiba. Anais... Curitiba: PUCPR, 2009.

TELLES, Vera da Silva. Direitos sociais: afinal do que se trata? Belo Horizonte: Editora da UFMG, 1999.

THEODORO, Mario. Questão racial e ações afirmativas: enfrentando o racismo e as desigualdades raciais na educação. GENTILI, Pablo (Org.). Política educacional, cidadania e conquistas democráticas. São Paulo: Fundação Perseu Abramo, 2013.

\section{LUIZ CARLOS GIL ESTEVES}

Professor e pesquisador da Pós-Graduação em Educação da Universidade Federal do Estado do Rio de Janeiro (UniRio). Professor adjunto da Universidade do Estado do Rio de Janeiro (UERJ), Rio de Janeiro, Rio de Janeiro, Brasil luizesteves@yahoo.com.br 